\title{
Meteorological factors affecting dengue incidence in Davao, Philippines
}

\author{
Jesavel A. Iguchi ${ }^{1}$, Xerxes T. Seposo ${ }^{2^{*}}$ and Yasushi Honda ${ }^{3}$
}

\begin{abstract}
Background: Dengue fever is a major public health concern in the Philippines, and has been a significant cause of hospitalizations and deaths among young children. Previous literature links climate change to dengue, and with increasingly unpredictable changing climate patterns, there is a need to understand how these meteorological variables affect dengue incidence in a highly endemic area.

Methods: Weekly dengue incidences (2011-2015) in Davao Region, Philippines were obtained from the Department of Health. Same period of weekly local meteorological variables were obtained from the National Climatic Data Center (NCDC) and the National Oceanic and Atmospheric Administration (NOAA). Wavelet coherence analysis was used to determine the presence of non-stationary relationships, while a quasi-Poisson regression combined with distributed lag nonlinear model (DLNM) was used to analyze the association between meteorological variables and dengue incidences.

Results: Significant periodicity was detected in the 7 to 14-week band between the year 2011-2012 and a 26-week periodicity from the year 2013-2014. Overall cumulative risks were particularly high for rainfall at $32 \mathrm{~mm}$ (RR: 1.67, 95\% Cl: 1.07-2.62), while risks were observed to increase with increasing dew point. On the other hand, lower average temperature of $26^{\circ} \mathrm{C}$ has resulted to an increased RR of dengue (RR: 1.96, 95\% Cl: $0.47-8.15$ ) while higher temperature from $27^{\circ} \mathrm{C}$ to $31^{\circ} \mathrm{C}$ has lower RR.
\end{abstract}

Conclusions: The observed possible threshold levels of these meteorological variables can be integrated into an early warning system to enhance dengue prediction for better vector control and management in the future.

Keywords: Dengue, Meteorological, Aedes, Rainfall, Temperature, Distributed lag nonlinear model, Wavelet analysis, Time series, Philippines

\section{Background}

Dengue fever is a common mosquito-borne viral disease of humans transmitted by the bite of an infected female adult mosquito namely the Aedes aegypti as the primary vector and Aedes albopictus as the secondary vector. Aedes aegypti is a holometabolous insect with a life cycle consisting of four stages, namely: egg, instars, pupa and adult [1]. It is characterized with a round or globular head structure, a white flat scales in the middle vertex and a slender, black, long and cylindrical proboscis [2]. Dengue can cause fatal complications such as dengue haemorrhagic fever (DHF) and dengue shock syndrome [3] . Dengue virus belongs to the single-stranded RNA virus of the Flaviviridae family that has four viral

\footnotetext{
* Correspondence: seposo.xerxestesoro.5w@kyoto-u.ac.jp

${ }^{2}$ Department of Environmental Engineering, Graduate School of Engineering, Kyoto University, Kyoto 615-8530, Japan

Full list of author information is available at the end of the article
}

serotypes namely; DEN-1, DEN-2, DEN-3, DEN-4 [4]. The adult female Aedes aegypti, the primary vector is a small, black mosquito with white markings around its body. Frequently, mosquito vectors lay its eggs in places within or near human dwellings; with only female adult mosquitoes transmitting the dengue virus $[3,5]$.

Dengue remains a major public health concern in tropical and subtropical areas [3]. Over the last 50 years, dengue incidence has increased by 30 -fold and around 2 . 5 billion people live in areas where dengue is endemic. Moreover, an estimated 50-200 million cases of dengue infections occur annually in the world [6]. The spread of dengue may be partly due to the increase of international travel, unplanned urbanization, rapid increase in population growth, lack of effective vector management, climate change and extreme weather events, and poor socio-economic status [7-9].

(c) The Author(s). 2018 Open Access This article is distributed under the terms of the Creative Commons Attribution 4.0 International License (http://creativecommons.org/licenses/by/4.0/), which permits unrestricted use, distribution, and 
Dengue disease has risen in an alarming state in the Philippines in recent years. From January 1st to August 6th of 2016, the Philippines' Department of Health $(\mathrm{DOH})$ reported an estimated suspected dengue cases of 84,085 in the country, which is $15.8 \%$ higher compared to the same period of last year in 2015 with only 72,627 reported cases; out of this, 372 resulted to death [10]. Out of the 10 Association of South East Asian Nations (ASEAN), the Philippines ranked fourth for having the highest number of dengue cases as of 2012 [11]. This alarming rate is partly due to several factors such as environmental degradation, climatic condition, lack of clean water supply, inappropriate waste disposal and management, rapid urbanization, increasing population, and poor mosquito surveillance and control system all contributed to the increasing number of dengue cases in the country [12].

The increasing dengue incidence worldwide is caused by several factors and one of them, which is our primary focus, are the meteorological factors. Change in these factors is believed to influence people's health through the spread of vector-borne diseases [8]. For example, meteorological factors such as temperature, rainfall, and humidity influence the life stages of female adult Aedes mosquitoes. A warm temperature is important to adult mosquitos' behavior and maturation, especially the larval development rate is shortened $[13,14]$. In addition, rainfall provides plenty of breeding sites for mosquito vectors such as puddles, while humidity affects the adult mosquitoes' survival and biting frequency [15].

Many countries have conducted studies on the relationship between meteorological factors and dengue cases. For instance, in the temperature and dengue relationship studies, different lagged effect was observed. An increase in $R R$ of dengue was reported to be related with an increase in minimum and maximum temperature by up to 1 to 2-month lag period in Brazil [16] and a lag of 1 month for maximum temperature in Mexico [17]. Meanwhile, a longer lag of up to 3 to 4 months was observed in Australia [18] and Barbados [19]. Furthermore, cumulative rainfall and dengue have also been found to have a varying lag effect; such as a 2-week lag in Mexico [20], a 4-week lag in Thailand [21], and a 10-week lag in Taiwan [22]. The differences on the effects of weather on dengue incidences could be due to the different variations of the amount of rainfall or the range of temperatures in the different regions with respect to their geographical locations [23].

Various approaches have been utilized to estimate the risks and the associated delayed risks of various local meteorological variables on dengue incidence, with a variety of linear [24] and non-linear models [25]. Recent methodological advancements have resulted to the utilization of a distributed lag nonlinear model (DLNM)
[26], taking into account the bi-dimensionality of the risks, exposure and lag components, evident in previous studies [27-30]. Further methodological specifications of DLNM are extensively discussed elsewhere [26, 31, 32]. Here, we aim to elucidate the effects of the local meteorological variables, one of the significant driving forces on dengue transmission [33]. This will enable us to determine the period of high risk of dengue infection since we hypothesized that, local meteorological factors may have an impact on the dengue incidences in Davao Region, Philippines. Clarifying the effects of these meteorological factors on dengue could provide an insight into the seasonal mechanisms of the disease thereby rendering information to understand the complex relationship between meteorological factors and health. Moreover, this study could provide valuable information to health officers for a more effective management of the disease for its control and prevention.

\section{Methods \\ Study area}

The study site is located in Davao Region, which is situated at the southeastern portion of the third largest island in the Philippines called Mindanao at $7^{\circ} 05^{\prime}$ latitude North and $125^{\circ} 35^{\prime}$ longitude East (Fig. 1). It is comprised of five provinces namely Compostela Valley, Davao del Norte, Davao del Sur, Davao Oriental, Davao Occidental [34]. It has a total land area of $20,357 \mathrm{~km}^{2}$ and with a total population of 4,893,318 in 2015 [35], making it the country's fifth fastest growing in terms of the population and $5 \%$ in the whole country [36]. The climate is tropical with two distinct seasons: a dry and wet season. According to the Philippine Atmospheric Geophysical and Astronomical Services Administration (PAGASA), wet season occurs from the months of April to October, while dry season occurs from the months of November to March [37]. There are four existing climate types in the Philippines based on the country's modified Coronas classification, namely Type I (dry from November to April, wet from May to October), Type II (seasonal rainfall from November to December), Type III (same as Type I, but with maximum rainfall from May to October) and Type IV (even distribution of rainfall year-round) [38]. Davao region is classified under Type IV with an annual average temperature of $28^{\circ} \mathrm{C}$; a temperature average shared with other major cities across the country [39].

\section{Data collection}

We conducted a retrospective time-series study of weekly dengue incidences and meteorological variables in Davao Region from 2011 to 2015 . Weekly secondary data of dengue incidences were obtained from the Department of Health-Davao Region (DOH-Region XI) 


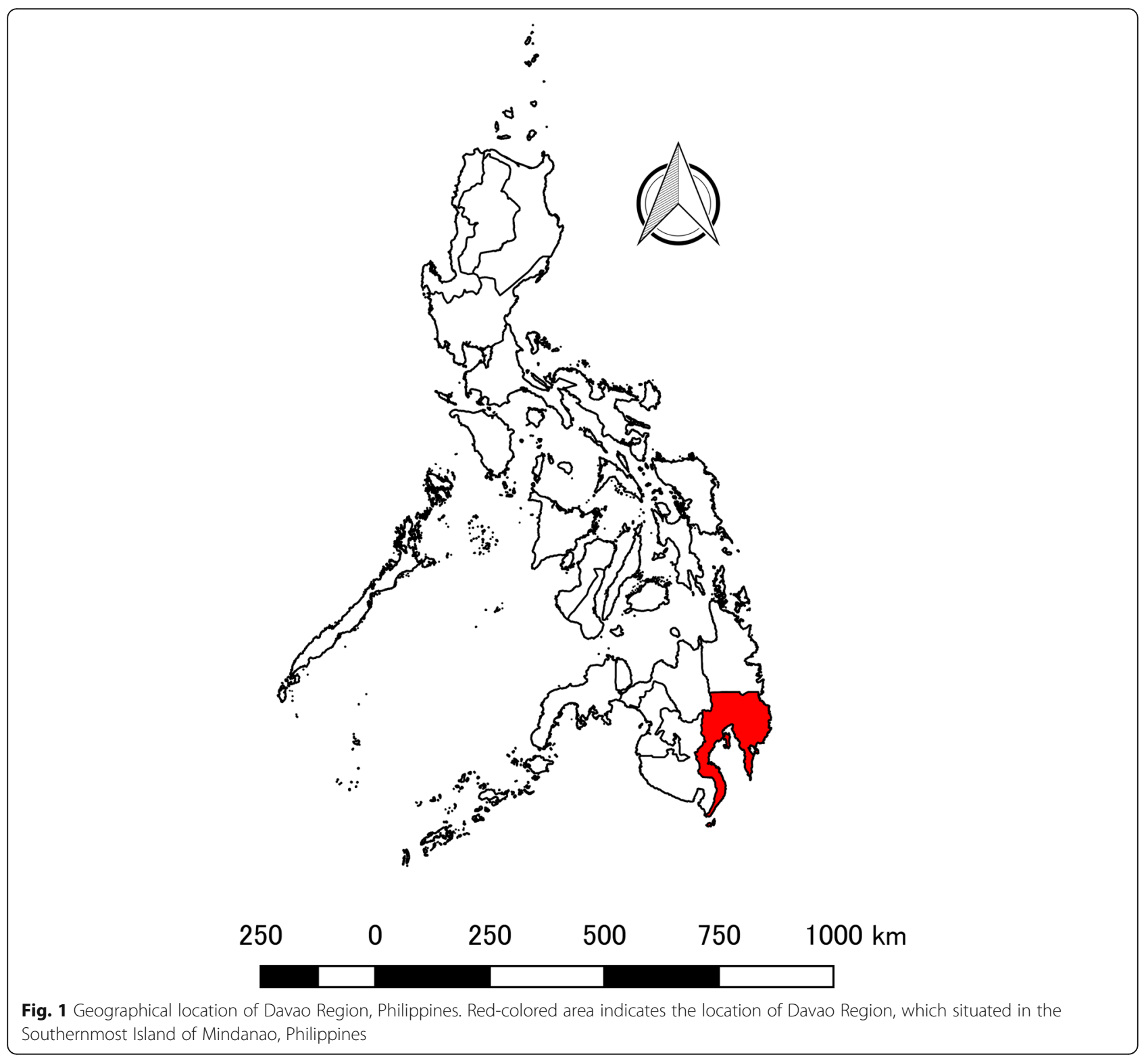

[40] and was freely available through formal data request. The case classification for the dengue incidences used in this study were based on the standard definitions of $\mathrm{DOH}$ and were not laboratory confirmed. The meteorological variables of interest, daily average temperature $\left({ }^{\circ} \mathrm{C}\right)$, cumulative rainfall per week $(\mathrm{mm})$, and dew point $\left({ }^{\circ} \mathrm{C}\right)$ reported by Francisco Bangoy International Airport in Davao City, Philippines, were extracted from the climate prediction center of the US National Weather Service website NOAA and NCDC (https://www.ncdc.noaa.gov/), which were then aggregated to weekly measures. Daily average temperature was computed as the mean of daily maximum and minimum temperatures. Weekly average temperature, dew point, and weekly cumulative rainfall were generated from the average of the seven-day daily observations for each meteorological variable.

\section{Statistical analyses \\ Wavelet coherence analysis}

This was performed to detect changes in the periodicity in the dengue incidence time series. According to Cazelles et al. [41] wavelet approach extracts the time and frequency of a time series and it is the most efficient method in studying non-stationary data. It transforms a time series into a wave [42]. Furthermore, wavelet was used in this study to determine whether the presence of a particular periodic frequency at a given time in dengue incidences corresponded to the presence of the same periodic frequency at the same time in the given meteorological variables [43]. 


\section{Distributed lag nonlinear model}

A quasi-Poisson time series model coupled with DLNM, which was introduced by Armstrong in 2006 [44] and expanded by Gasparrini in 2010 [31, 32], was used to assess the impact of meteorological variables on dengue incidences. The relationship between meteorological factors and diseases are seldom linear, and the former's effect are commonly delayed [45]. DLNM uses a crossbasis function, which enables users to explore the association between the exposure variable and its lag, which is in weeks in this instance [46]. We assumed that the reported dengue incidences, $y$, at week $t$, follows an overdispersed quasi-Poisson distribution and can be written as shown below:

\section{$y_{t} \sim$ quasipoisson}

$$
\begin{aligned}
\log \left(\mathrm{E}\left(y_{t}\right)\right]= & \alpha+\beta_{1} \text { Rainfall }_{t, l} \\
& +n s(\text { Week }, 4 \times 5)
\end{aligned}
$$

Where $y_{t}$ refers to the weekly dengue incidences on week $t$, while $t$ denotes the week of the observation, $\alpha$ is the model intercept, Rainfall $t, l$ is the cross-basis matrix for cumulative rainfall as a covariate on time $(t)$ with 4 degrees of freedom $(d f), l$ is the lag in weeks, $n s$ is the smoothing parameter specified on a natural cubic spline (NCS), Week is assigned to control for the seasonal variation.

Moreover, we conducted the DLNM analysis for a maximum lag of 12 weeks. For other meteorological variables, we replaced the cross-basis of the rainfall in Eq. 1 with the respective cross-basis of the other meteorological variables. Model selection was facilitated using three performance indicators namely, Quasi-Akaike Information Criterion (QAIC), Root Mean Squared Error (RMSE) and R-squared as indicated in Table 1. For comparison, we also assumed a simple linear regression with the same specifications.
All the statistical analyses were performed using $\mathrm{R}$ software program, version 3.3.1 [47], while the map figure was created using QGIS version 3.0 [48].

\section{Sensitivity analyses}

The passive surveillance system, utilized by the country, is prone to under-reporting and may have considerable impact on the effects estimate [49]. To establish the robustness of the effects estimates, we applied an expansion factor (EF) of 7.0 for the suspected number of cases [11, 50]. EFs have been utilized to adjust for the underreporting of the total number of cases from surveillance systems [50]. For model performance, we further analyzed for a multivariate model with DLNM and simple linear models (in Additional file 1: Table S1).

\section{Results}

\section{Dengue incidence distribution}

Table 2 shows the descriptive statistics of both weekly dengue incidences and local meteorological variables in Davao Region from 2011 to 2015. From 2011 to 2015, there were 38,169 dengue cases reported at the $\mathrm{DOH}$ Davao Region. In the study period, dengue increased from 4115 cases in 2011 to 9507 cases in 2012, and reached a peak in the year 2013 with 10,762 cases, the highest reported number of dengue cases within the study period. Then, it gradually decreased to 8643 in 2014 and at 5142 cases in 2015 (Fig. 2). The highest reported number of dengue was at the $6^{\text {th }}$ week of the year 2013 around the month of February (Additional files 2 and 3: Figures $\mathrm{S} 2$ and S3A) with 442 cases while the lowest was in the $13^{\text {th }}$ week around the month of March 2015 with 30 cases.

Figure 3 represents the time trend of the weekly dengue incidences and local meteorological variables in Davao Region. The data showed that the number of dengue incidences were high from the year 2012, 2013 and 2014 (Fig. 3a). A higher number of dengue generally occurred

\begin{tabular}{|c|c|c|c|c|}
\hline Models & & QAIC & RMSE & pseudo R-squared \\
\hline Intercept only & & $13,869.39$ & - & - \\
\hline \multicolumn{5}{|c|}{ Simple Linear Models } \\
\hline & w/ Rainfall & 6088.93 & 0.3292689 & 0.6785798 \\
\hline & w/ Average temperature & 5866.015 & 0.3222838 & 0.6954379 \\
\hline & w/ Dew point & 5456.907 & 0.3183454 & $0.7251268^{a}$ \\
\hline \multicolumn{5}{|l|}{ DLNM Models } \\
\hline & w/ Rainfall & 4313.961 & 0.241543 & 0.8085139 \\
\hline & w/ Average temperature & 4291.979 & 0.251437 & 0.8112628 \\
\hline & w/ Dew point & 4002.741 & 0.2350322 & $0.8321903^{b}$ \\
\hline
\end{tabular}

Table 1 The QAIC, RMSE and pseudo R-squared values for the selected models

QAIC Quasi-Akaike Information Criterion, RMSE Root Mean Squared Error

aest predictor among simple linear models

${ }^{\mathrm{b}}$ Best predictor among the DLNM models 
Table 2 Descriptive statistics of the weekly dengue incidences and local meteorological variables in Davao Region, 2011-2015

\begin{tabular}{lllll}
\hline & Minimum & Maximum & Mean & Standard deviation \\
\hline Dengue incidence & 30 & 442 & 146.80 & 85.91 \\
Average temperature $\left({ }^{\circ} \mathrm{C}\right)$ & 25.9 & 30.9 & 28.4 & 0.8 \\
Rainfall $(\mathrm{mm})$ & 0.0 & 102.3 & 14.1 & 16.8 \\
Dew point $\left({ }^{\circ} \mathrm{C}\right)$ & 21.3 & 25.9 & 24.5 & 0.8 \\
\hline
\end{tabular}

from the rainy months of June throughout October (Additional file 3: Figure S3A), which consequently falls within the same period of the annual monsoon rains.

\section{Temperature and rainfall distribution}

The highest weekly average temperature recorded within the study period was $30.9{ }^{\circ} \mathrm{C}$ in the $18^{\text {th }}$ week of 2014 around the month of May (Fig. $3 \mathrm{~b}$ and Additional file 2: Figure S2), which is the second hottest month of the year after April, followed by $30.3{ }^{\circ} \mathrm{C}$ in the $18^{\text {th }}$ week of 2013 on the same month. Meanwhile, the lowest weekly average temperature recorded was $25.9{ }^{\circ} \mathrm{C}$ in the $2^{\text {nd }}$ week of 2014 around the month of January (Additional file 3: Figure S3B).

Between the study period from 2011 to 2015, 2012 has the largest volume of cumulative rainfall recorded at around $823.0 \mathrm{~mm}$, while the smallest volume of rainfall was in 2015 with $604.0 \mathrm{~mm}$ (Table 3 and Additional file 4: Figure S1). The highest weekly cumulative rainfall reported was around the 51st week of 2013 around the month of December with $102.3 \mathrm{~mm}$ of rainfall (Fig. 3c and Additional file 3: Figure S3C).

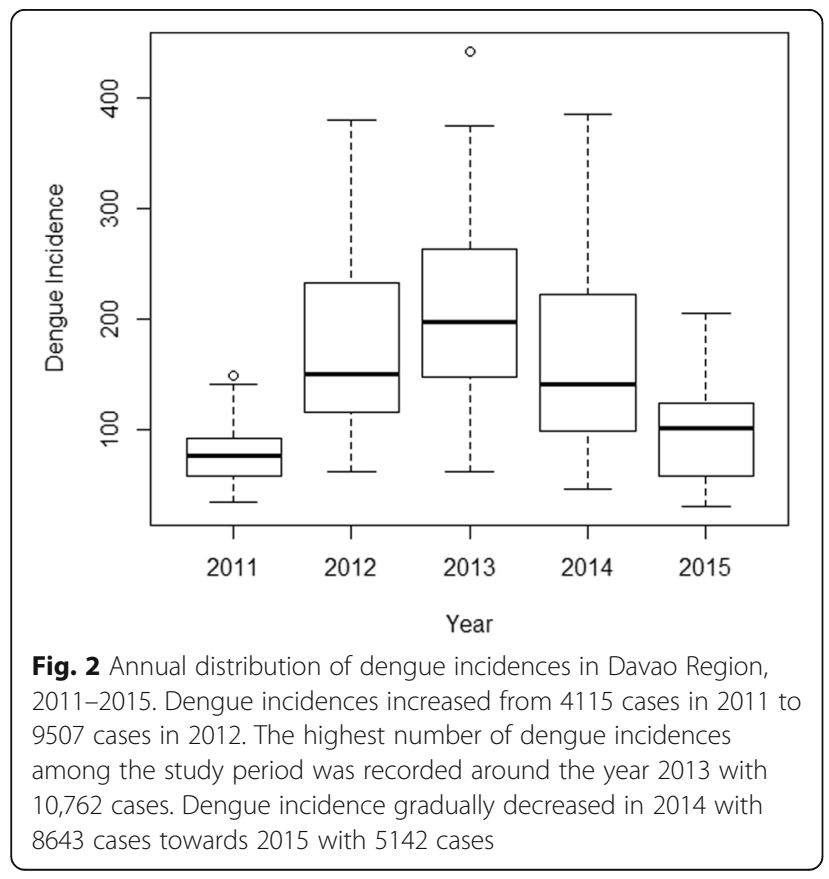

\section{Coherence between local meteorological variables and dengue}

Wavelet coherence analysis was used to detect periodicity between dengue incidences and local meteorological variables. In Fig. 4, the coherence between dengue incidences and local meteorological variables varied at different periods and the periodicity of the signals were different through time. For the average temperature and dengue incidences, there were significant periodicities detected in the 7- to 14-week band between the year 2011-2012 and a 26-week periodicity was also observed from the year 2013-2014. There were also several mild periodicities at 2- to 6-week periods that appear in an occasional pattern (Fig. 4a). Likewise, for the cumulative rainfall and dengue incidences, wavelet analysis showed a significant 32-week periodicity band from 2011 to 2012 and an 18- to 30-week periodicity from 2013 to 2014. Furthermore, several high periodicities were also observed in an infrequent pattern at around 2- to 10-week bands (Fig. 4b). For dew point and dengue incidences, wavelet results revealed a significant periodicity of a 20- to 26-week from 2012 to 2013 as well as a 50- to 60-week band from 2011 to 2015. There were also several high frequency periodicities at 2- to 6week (Fig. 4c).

\section{Relationship of climate variables and dengue}

To analyze the relationship between local meteorological variables and dengue incidences, a quasi-Poisson time series combined with DLNM was used. The effect of rainfall on dengue were different between low and high cumulative rainfall. As shown in the overall cumulative plot, risk was gradually increasing from 20 to $40 \mathrm{~mm}$ of rainfall, with a peak at $32 \mathrm{~mm}$ (RR: 1.67, 95\% CI: 1.07-2. $62)$. On the other hand, lower average temperature of $26{ }^{\circ} \mathrm{C}$ has resulted to an increased RR of dengue (RR: 1 . 96, 95\% CI: 0.47-8.15) while higher temperature from $27{ }^{\circ} \mathrm{C}$ to $31{ }^{\circ} \mathrm{C}$ has lower RR (Fig. 5b). Meanwhile, for dew point, risks were increasing $25.3^{\circ} \mathrm{C}$. The highest RR was observed at dew point value of $26^{\circ} \mathrm{C}$ (RR: $3.10,95 \%$ CI: 1.20-8.06) (Fig. 5c).

\section{Discussion}

In this study, we have observed significant but varying non-stationary periodicities between the local meteorological variables and that of dengue incidence. Further 


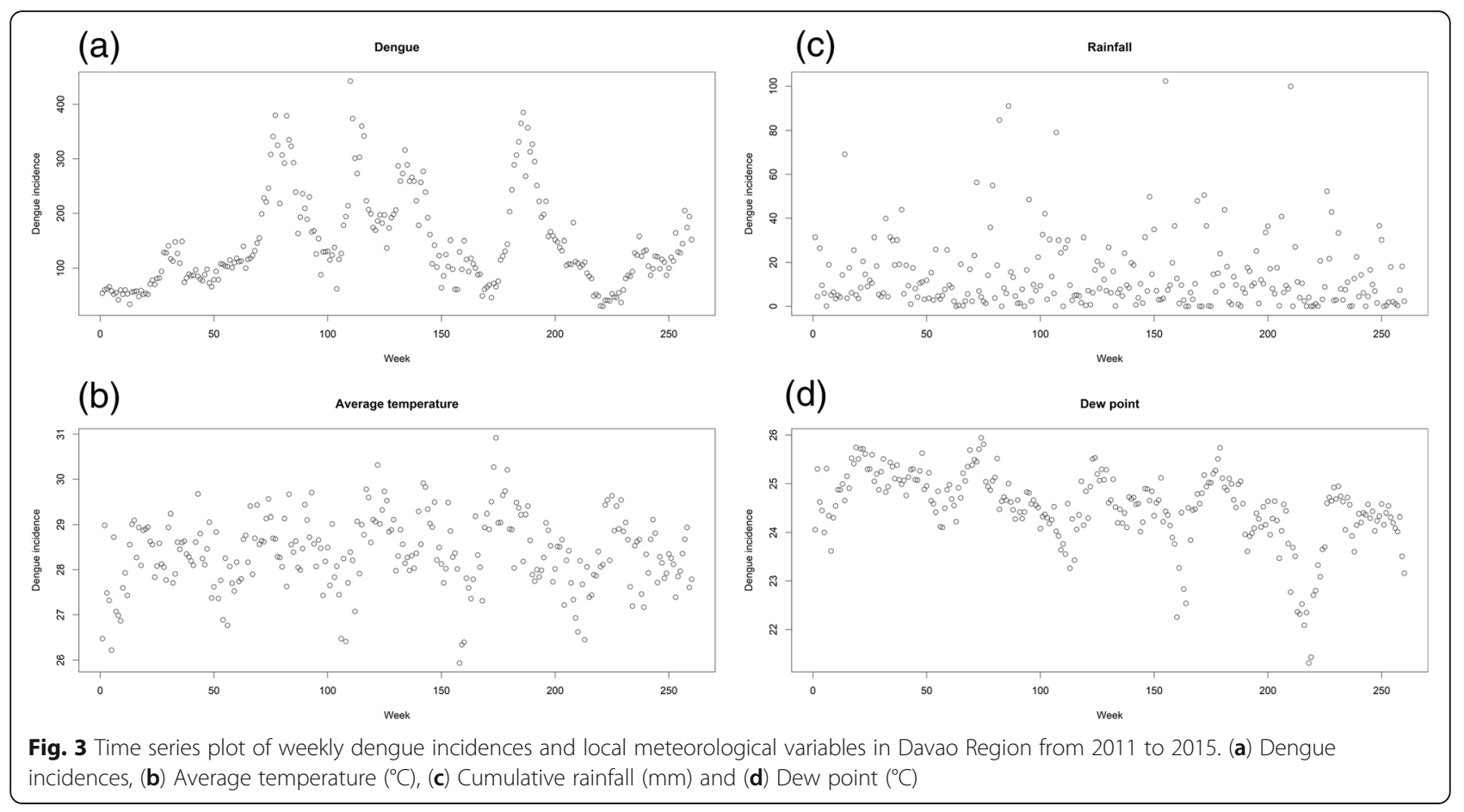

analysis indicated the effects of the varying levels of meteorological variables on dengue incidence. Findings from our study can be utilized for an integrated dengue early warning system, relevant for disease control and management.

In Fig. 4, we have observed significant, but varying inter-annual periodicities of dengue incidence with respect to the specific meteorological variables of interest. In particular, there are consistent longer significant bands from the 16th to 32nd week, for all the three local variables, which coincides with the summer month of April and gradually transitions towards the rainy month of August. There are also small pockets of significant mild periodicities in the 4th to 16th week across the years amongst the three meteorological variables, however, we have observed a significant inter-annual periodicity (2010-2012) from the 6th week to the 15th week, dry season, apparent only with average temperature. Though some studies have noted that mosquito activity would be high in the rainy periods, there are indications that even in dry season mosquito activity may be heightened. Wai et al. [51] observed that vector breeding was enhanced in the dry season in the Philippines due to the presence of water storage, conducive for mosquito growth and development. Tsuzuki et al. [52] also noted the potential of dengue transmission even in hot-dry periods in Nha Trang, Viet Nam, with similarly possible linkage to unchecked and left out indoor water containers.

Beyond the non-stationary relationship observed in the wavelet coherence patterns, we further investigated the impact of local meteorological variables on the dengue morbidity, with the primary focus on identifying the lag (weeks) in which dengue cases has occurred. Based on DLNM, there was a positive association between rainfall, average temperature and dew point with dengue cases. We found that, a moderate amount of rainfall has resulted with increasing RR and gradually decreased as the amount of rainfall increased.

Our findings are consistent with previous studies, whereby a high occurrence of dengue in the few weeks were also observed after moderate rainfall. Ehelepola

Table 3 Annual distribution of dengue incidences and local meteorological variables in Davao Region, 2011-2015

\begin{tabular}{lllll}
\hline Period & Dengue incidences & Average temperature $\left({ }^{\circ} \mathrm{C}\right)$ & Rainfall $(\mathrm{mm})$ & Dew point $\left({ }^{\circ} \mathrm{C}\right)$ \\
\hline 2011 & 4115 & 28.2 & 744.5 & 25.1 \\
2012 & 9507 & 28.4 & 823.0 & 24.8 \\
2013 & 10,762 & 28.6 & 796.4 & 24.5 \\
2014 & 8643 & 28.5 & 697.7 & 24.4 \\
2015 & 5142 & 28.2 & 604.0 & 23.8 \\
\hline
\end{tabular}




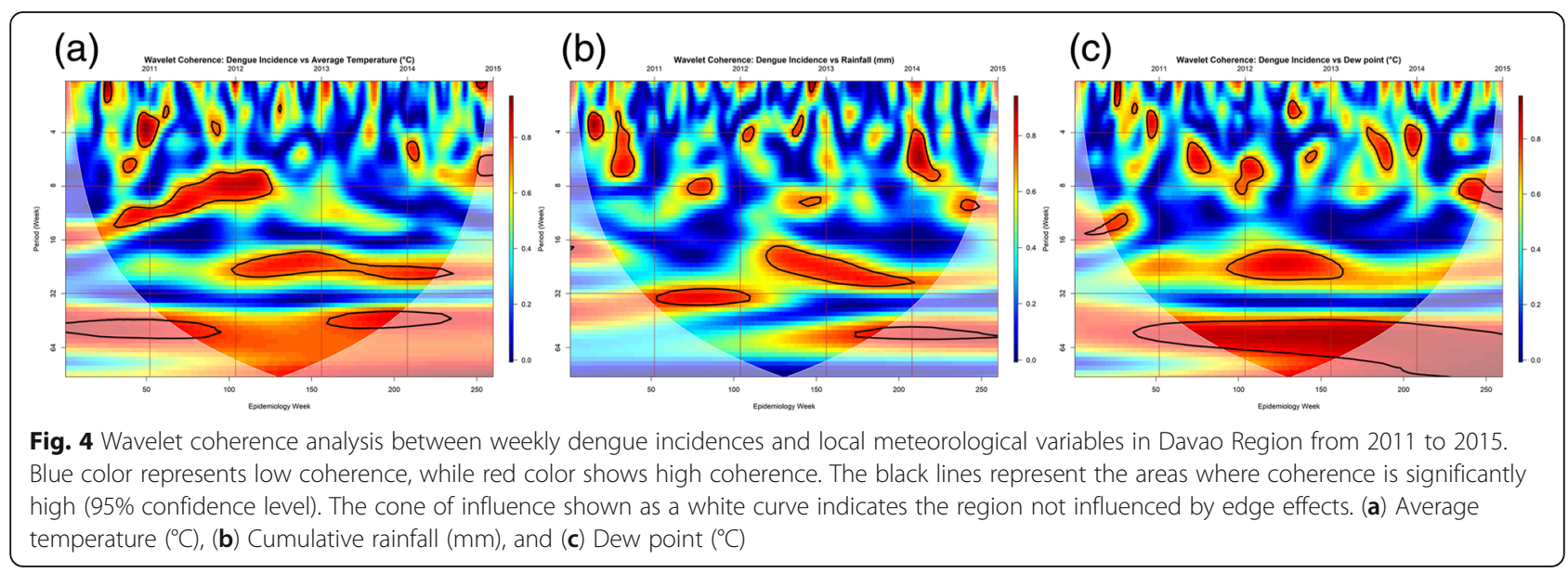

et al. [53] have found that regular rain favors an increase in dengue but not heavy rain. Similarly, Sarfraz [54] noted that heavy rainfalls may flush away the eggs, larvae and pupae of dengue mosquitoes, which could have consequently affected the mosquito abundance [55]. On the other hand, we have observed that moderate amount of rainfall $(20-30 \mathrm{~mm})$ was related to higher dengue incidences in Davao Region. Eastin et al. [56] and Hii et al. [5] noted that light to moderate rainfall can increase the usage of water containers, which are conducive breeding sites for the mosquito.

According to DOH, Davao City which is located near Davao del Sur and a highly urbanized area in Davao
Region, has always had the highest number of dengue, comprising around $70 \%$ of the cases [57] while the rest are from the neighboring provinces. Dengue is usually higher in highly urbanized areas like cities, where there is overcrowding and poor environmental waste management [58]. In 2013, there was a spike in dengue incidence in Davao City, which was assumed to be linked to the lack of cleanliness drive, unpredictable weather conditions and floods in the area [59] despite the increasing exertion of the DOH and the local health units in Davao Region on the implementation of dengue vector control programs throughout the years. One of the initiated clean-up activities by the DOH is the 4 o'clock habit,

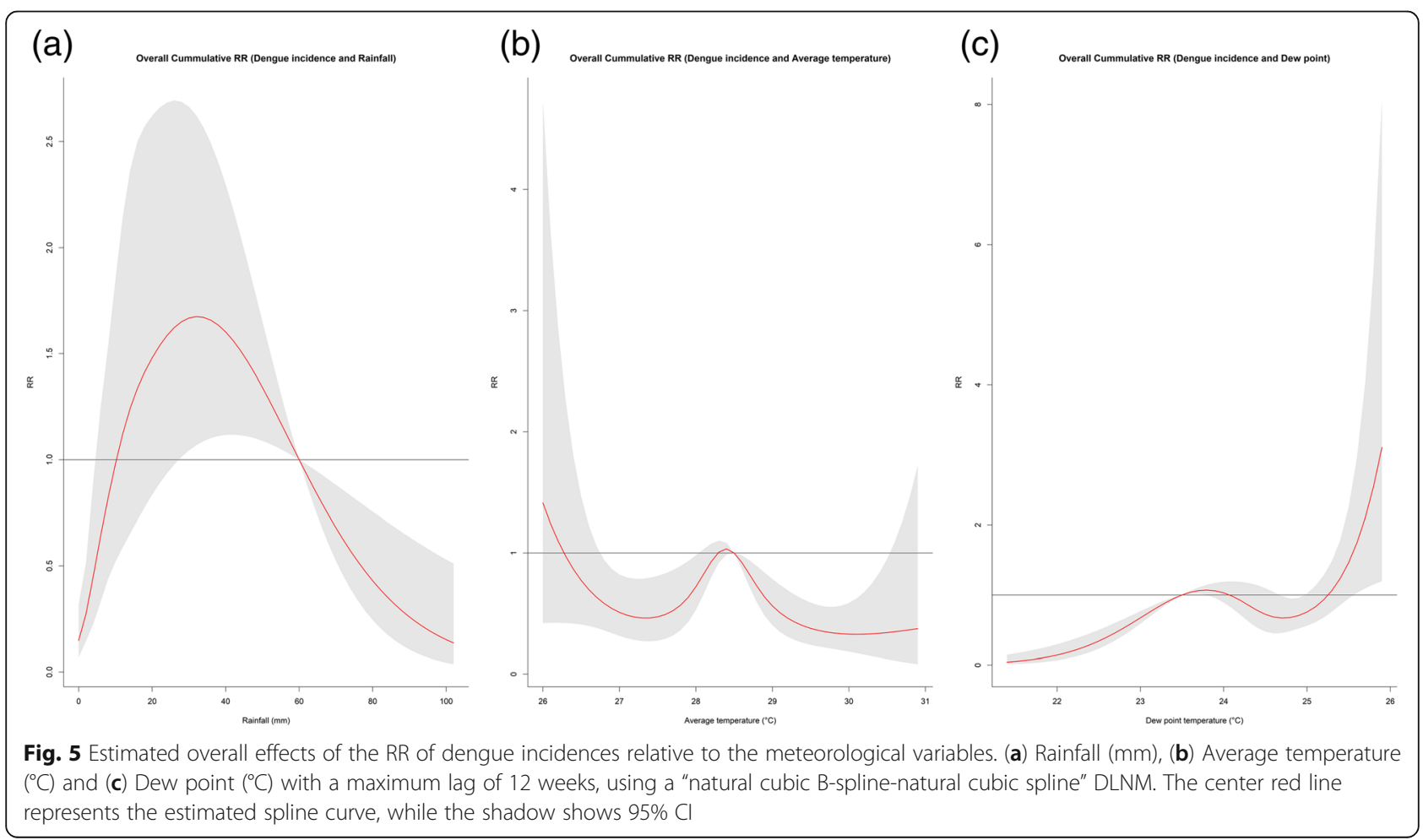


which entails the search and destruction of possible mosquito breeding sites, usually done in four in the afternoon [59].

Average temperature at $26{ }^{\circ} \mathrm{C}$ has resulted to an increased RR, while higher temperature from $27^{\circ} \mathrm{C}$ to $31^{\circ}$ $\mathrm{C}$ has lower RR. This was suggestive of the established fact that mosquito development has an optimum range of 25 to $27{ }^{\circ} \mathrm{C}$ [60]. This optimum temperature for mosquito strongly enhanced the development from larva to adult, the biting frequency in humans, and the extrinsic incubation period of dengue virus in the mosquito. The decrease in the $R R$ of temperatures from $27{ }^{\circ} \mathrm{C}$ to $31{ }^{\circ} \mathrm{C}$ is indicative that higher temperature above the optimum range for the Aedes mosquito development brings about a protective effect on dengue transmission [61], as observed in Fig. 5. Higher temperatures may have a negative effect on adult life span of mosquitoes, thereby affecting consequent transmission [62]. In particular, reduced vector competence and activity may result from an increased temperature [63].

Beyond a dew point temperature of $25.3{ }^{\circ} \mathrm{C}$, risks were apparently increasing. Similar observations of significant relationship by dew point on dengue incidence was observed in Brazil [64]. Mechanisms of how dew point affects dengue incidence maybe related to that of the mechanisms posed by humidity. Mathematically and theoretically, dew point and humidity have a nearly linear relationship [65]. Taking this into account, we can observe an identical J-shaped pattern of absolute humidity and RR in a study done in Singapore [29] compared to Fig. 4. High humidity favors an increased longevity of adult mosquitoes as well as the shortening of viral incubation period, thereby allowing an increased transmission intensity [66].

We acknowledge that under-estimation of the burden poses one of the few challenges in establishing the robustness of the effects estimates in this study. However, even after applying an EF of 7, effects estimates as well as the risk curve remained the same, making the estimates robust (in Additional file 5: Figure S4). Furthermore, a recent study in the Philippines noted a high proportion of laboratory confirmed cases (86.1\%) from the suspected cases, which thereby indicate that accuracy of clinical diagnosis at admission [67].

This is the very first study in the Philippines which extensively described the association between local meteorological variables and dengue incidences. This study could help improve the dengue surveillance system in the country by taking into account the underlying mechanisms which could be framed in the context of non-stationary relationship as well as the candidate threshold levels, for better dengue prediction. Furthermore, we also acknowledge some limitations in this study. First, the weekly dengue data used in this study were notified suspected dengue cases from clinics and hospitals and are not laboratory confirmed. Second, we did not take into account the mosquito density, population immunity, age classification, social behavior, and socioeconomic conditions for these data are unavailable.

\section{Conclusions}

The meteorological variables, though may have varying effects on dengue incidence, exhibit associations which coincide with the plausible biological pathways. Risks were particularly higher in meteorological events with moderate rain, low temperature and high dew point. Furthermore, the observed possible threshold levels of these meteorological variables can be integrated into an early warning system to enhance dengue prediction for better vector control and management in the future.

\section{Additional files}

\begin{abstract}
Additional file 1: Table S1. Sensitivity analysis with the combination of DLNM and simple linear models. The table depicts that no matter the combination of the linear and DLNM models, there is not much improvement in the model performance, with similar observations in the previous univariate linear and DLNM models. (DOCX $14 \mathrm{~kb}$ )

Additional file 2: Figure S2. Weekly distribution of dengue incidence, average temperature, and cumulative rainfall from 2011 to 2015 in Davao Region. Red line is the cumulative rainfall, dotted blue line are the dengue incidences, and the green dot-and-line is the average temperature. The right-hand side $y$-axis is in degrees Celsius (for the average temperature), while the left-hand side $y$-axis is for the dengue incidence and rainfall levels. (JPEG $38 \mathrm{~kb}$ )
\end{abstract}

Additional file 3: Figure S3. Distribution of monthly dengue incidences and local meteorological variables from 2011 to 2015. (A) Box plot of the monthly dengue incidences, (B) Average temperature $\left({ }^{\circ} \mathrm{C}\right)$, (C) Cumulative rainfall $(\mathrm{mm})$, and (D) Dew point $\left({ }^{\circ} \mathrm{C}\right)$. The horizontal line in the middle of each box is the mean, while the top and bottom borders of the box represent the 25 th and 75 th percentiles, respectively and the whiskers indicates the 10th and 90th percentiles. (TIF $234 \mathrm{~kb}$ )

Additional file 4: Figure S1. Annual distribution of cumulative rainfall $(\mathrm{mm})$ in Davao Region, 2011-2015. Annual variations in the rainfall, with 2012 recording the highest level (of rainfall). (TIFF $6784 \mathrm{~kb}$ )

Additional file 5: Figure S4. EF-applied dose-response risk curve. Relatively the same risk patterns can be observed, with heightened risks for moderate rain, low temperature and high dew point. (TIFF $1551 \mathrm{~kb}$ )

\section{Abbreviations}

ASEAN: Association of South East Asian Nations; DHF: Dengue haemorrhagic fever; DLNM: Distributed lag nonlinear model; DOH: Department of Health; EF: Expansion Factor; NCDC: National Climatic Data Center; NCS: Natural cubic spline; NOAA: National Oceanic and Atmospheric Administration; PAGASA: Philippine Atmospheric Geophysical and Astronomical Services Administration; QAIC: Quasi-Akaike Information Criterion; RMSE: Root Mean Squared Error; RR - Relative risk

\section{Acknowledgements}

We would also like to thank the National Oceanic and Atmospheric Administration for the meteorological data, as well as the Department of Health-Davao Region (Region XI) regional director Dr. Abdullah B. Dumama Jr., for generously providing the weekly dengue data report. Without their generosity, this study wouldn't be possible. 


\section{Funding}

This research is supported by the Environment Research and Technology Development Fund (S-10 and S-14) of the Ministry of the Environment, Japan, and by the Global Research Laboratory grant (Grant K2100400000110A0500-00710) through the National Research Foundation of Korea, which is funded by the Ministry of Education, Science and Technology, Korea.

\section{Availability of data and materials}

The availability of data is subject to both request from the first author, and the approval from the respective data handler; in this case the $\mathrm{DOH}$ - Davao Region.

\section{Authors' contributions}

JAl collected and analyzed the data. JAI wrote the manuscript. XTS analyzed the data. XTS and YH provided technical support, drafted and revised the manuscript. All authors read and approved the final manuscript.

\section{Ethics approval and consent to participate}

Since secondary data were utilized in this study, no ethics approval was necessary.

\section{Consent for publication}

No data or information in this study included an individual person's data.

\section{Competing interests}

The authors declare that they have no competing interests.

\section{Publisher's Note}

Springer Nature remains neutral with regard to jurisdictional claims in published maps and institutional affiliations.

\section{Author details}

'Department of Health Care Policy and Health Economics, Graduate School of Comprehensive Human Sciences, Ibaraki 305-8577, Japan. ${ }^{2}$ Department of Environmental Engineering, Graduate School of Engineering, Kyoto University, Kyoto 615-8530, Japan. ${ }^{3}$ Faculty of Health and Sports Sciences, University of Tsukuba, Ibaraki 305-8577, Japan.

\section{Received: 18 November 2017 Accepted: 1 May 2018} Published online: 15 May 2018

\section{References}

1. Farnesi LC, Brito JM, Linss JG, Pelajo-Machado M, Valle D, Physiological RGL. Morphological aspects of Aedes aegypti developing larvae: effects of the chitin synthesis inhibitor novaluron. PLoS One. 2012;7:e30363.

2. Andrew J, Bar A. Morphology and morphometry of Aedes aegypti adult mosquito. Annu Rev Res Biol. 2013;3:52-69.

3. Gubler DJ. Dengue and dengue hemorrhagic fever. Clin Microbiol Rev. 1998:11:480-96. https://doi.org/10.1016/S0140-6736(97)12483-7.

4. Johnson BW, Russell BJ, Lanciotti RS. Serotype-specific detection of dengue viruses in a Fourplex real-time reverse transcriptase PCR assay. J Clin Microbiol. 2005;43:4977-83

5. Hii YL, Rocklov J, Ng N, Tang CS, Pang FY, Sauerborn R. Climate variability and increase in intensity and magnitude of dengue incidence in Singapore. Glob Health Action. 2009;2

6. Murray NEA, Quam MB, Wilder-Smith A. Epidemiology of dengue: past, present and future prospects. Clinical Epidemiology. 2013;5:299-309.

7. Morin CW, Comrie AC, Climate EK. Dengue transmission: evidence and implications. Environ Health Perspect. 2013;121:1264-72.

8. Ebi KL, Nealon J. Dengue in a changing climate. Environ Res. 2016;151: $115-23$.

9. Naish S, Dale P, Mackenzie JS, McBride J, Mengersen K, Tong S. Climate change and dengue: a critical and systematic review of quantitative modelling approaches. BMC Infect Dis. 2014;14:167.

10. DOH: 372 deaths due to dengue since January. https://www.rappler.com/ nation/143318-doh-philippines-dengue-updates-january-august-2016. Accessed 11 Apr 2017.

11. Edillo FE, Halasa YA, Largo FM, Erasmo JNV, Amoin NB, Alera MTP, et al. Economic cost and burden of dengue in the Philippines. Am J Trop Med Hyg. 2015;92:360-6.
12. Bravo L, Roque VG, Brett J, Dizon R, L'Azou M. Epidemiology of dengue disease in the Philippines (2000-2011): a systematic literature review. PLoS Negl Trop Dis. 2014;8:e3027.

13. Focks DA, Haile DG, Daniels E, Mount GA. Dynamic life table model for Aedes aegypti (Diptera: Culicidae): analysis of the literature and model development. J Med Entomol. 1993;30:1003-17. https://doi.org/10.1093/ jmedent/30.6.1003.

14. Patz JA, Martens WJ, Focks DA, Jetten TH. Dengue fever epidemic potential as projected by general circulation models of global climate change. Env Heal Perspect. 1998;106:147-53.

15. Banu S, Guo Y, Hu W, Dale P, Mackenzie JS, Mengersen K, et al. Impacts of El Niño southern oscillation and Indian Ocean dipole on dengue incidence in Bangladesh. Sci Rep. 2015;5 NOVEMBER:16105. doi:https://doi.org/10. 1038/srep16105

16. Gomes AF, Nobre AA, Cruz OG. Temporal analysis of the relationship between dengue and meteorological variables in the city of Rio de Janeiro, Brazil, 2001-2009. Cad Saude Publica. 2012;28:2189-97. https://doi.org/10. 1590/S0102-311X2012001100018.

17. Chowell G, Sanchez F. Climate-based descriptive models of dengue fever: the 2002 epidemic in Colima, Mexico. J Environ Health. 2006;68: 40-4. 55

18. Bi P, Tong S, Donald K, Parton KA, Hobbs J. Climate variability and the denque outbreak in Townsville, Queensland, 1992-93. Environ Health. 2001; 1:54. http://search.informit.com.au/documentSummary; $d n=22929675151$ 6574;res=IELHEA

19. Depradine C, Lovell E. Climatological variables and the incidence of dengue fever in Barbados. Int J Environ Health Res. 2004;14:429-41. https://doi.org/ 10.1080/09603120400012868

20. Brunkard JM, Cifuentes E, Rothenberg SJ. Assessing the roles of temperature, precipitation, and ENSO in dengue re-emergence on the Texas-Mexico border region. Salud Publica Mex. 2008:50:227-34.

21. Jeefoo P, Tripathi NK, Souris M. Spatio-temporal diffusion pattern and hotspot detection of dengue in Chachoengsao province, Thailand. Int J Environ Res Public Health. 2011;8:51-74.

22. Chen MJ, Lin CY, Wu YT, Wu PC, Lung SC, Su HJ. Effects of extreme precipitation to the distribution of infectious diseases in Taiwan, 1994-2008. PLoS One. 2012;7:e34651.

23. Sun $W$, Xue L, Xie X. Spatial-temporal distribution of denque and climate characteristics for two clusters in Sri Lanka from 2012 to 2016. Sci Rep. 2017;7:12884.

24. Johansson MA, Reich NG, Hota A, Brownstein JS, Santillana M. Evaluating the performance of infectious disease forecasts: a comparison of climate-driven and seasonal dengue forecasts for Mexico. Sci Rep. 2016;6:33707.

25. Xiang J, Hansen A, Liu Q, Liu X, Tong MX, Sun Y, et al. Association between dengue fever incidence and meteorological factors in Guangzhou, China, 2005-2014. Environ Res. 2017;153:17-26.

26. Gasparrini A. Modeling exposure-lag-response associations with distributed lag non-linear models. Stat Med. 2014;33:881-99.

27. Choi Y, Tang CS, Mclver L, Hashizume M, Chan V, Abeyasinghe RR, et al. Effects of weather factors on dengue fever incidence and implications for interventions in Cambodia. BMC Public Health. 2016;16:241.

28. Horta MA, Bruniera R, Ker F, Catita C, Ferreira AP. Temporal relationship between environmental factors and the occurrence of dengue fever. Int J Environ Health Res. 2014;24:471-81.

29. Xu HY, Fu X, Lee LKH, Ma S, Goh KT, Wong J, et al. Statistical modeling reveals the effect of absolute humidity on dengue in Singapore. PLoS Negl Trop Dis. 2014;8:e2805

30. Chuang TW, Chaves LF, Chen PJ. Effects of local and regional climatic fluctuations on dengue outbreaks in southern Taiwan. PLoS One. 2017; 12:e0178698.

31. Gasparrini A. Distributed lag linear and non-linear models in R: the package dlnm. J Stat Softw. 2011;43:1-20.

32. Gasparrini A, Armstrong B, Kenward MG. Distributed lag non-linear models. Stat Med. 2010;29:2224-34. https://doi.org/10.1002/sim.3940.

33. Hales S, de Wet N, Maindonald J, Woodward A. Potential effect of population and climate changes on global distribution of dengue fever: an empirical model. Lancet. 2002;360:830-4. https://doi.org/10.1016/S01406736(02)09964-6.

34. PSA. Philippine Standard Geographic Code. http://nap.psa.gov.ph/ activestats/psgc/default.asp. Accessed 9 Apr 2017. 
35. PSA. Census of Population (2015): Highlights of the Philippine Population 2015 Census of Population. https://psa.gov.ph/content/highlightsphilippine-population-2015-census-population. Accessed 9 Apr 2017.

36. PSA. Population and Annual Growth Rates for The Philippines and Its Regions, Provinces, and Highly Urbanized Cities. 2010 Census and Housing Population. https://psa.gov.ph/sites/default/files/attachments/hsd/ pressrelease/Population and Annual Growth Rates for The Philippines and Its Regions\%2C Provinces\%2C and Highly Urbanized Cities Based on 1990\%2C 2000\%2C and 2010 Censuses.pdf. Accessed 9 Apr 2017.

37. PAGASA. http://www1.pagasa.dost.gov.ph/. Accessed 12 Apr 2017.

38. Seposo XT, Dang TN, Honda Y. Exploring the effects of high temperature on mortality in four cities in the Philippines using various heat wave definitions in different mortality subgroups. Glob Health Action. 2017;10:1368969.

39. Seposo XT, Dang TN, Honda Y. Effect modification in the temperature extremes by mortality subgroups among the tropical cities of the Philippines. Glob Health Action. 2016;9:31500. https://doi.org/10.3402/gha.v9.31500

40. DOH. DOH - Region XI. http://ro11.doh.gov.ph/. Accessed 12 Apr 2017.

41. Cazelles B, Chavez M, McMichael AJ, Hales S. Nonstationary influence of El $\mathrm{Ni}$ ??O on the synchronous dengue epidemics in Thailand. PLoS Med. 2005; 2:0313-8.

42. Johansson MA, Cummings DAT, Glass GE. Multiyear climate variability and dengue - El Nino southern oscillation, weather, and dengue incidence in Puerto Rico, Mexico, and Thailand: a longitudinal data analysis. PLoS Med. 2009;6:e1000168

43. Torrence C, Compo GPA. Practical guide to wavelet analysis. Bull Am Meteorol Soc. 1998;79:61-78.

44. Armstrong B. Models for the relationship between ambient temperature and daily mortality. Epidemiology. 2006;17:624-31. https://doi.org/10.1097/ 01.ede.0000239732.50999.8f.

45. Imai C, Armstrong B, Chalabi Z, Mangtani P, Hashizume M. Time series regression model for infectious disease and weather. Environ Res. 2015; 142:319-27

46. Talagala T. CLIMATIC FACTORS AND DENGUE INCIDENCE IN COLOMBO DISTRICT distributed lag nonlinear modelling approach to identify relationship between climatic factors and dengue incidence in Colombo District. Sri Lanka Epidemiol Biostat Public Heal. 2015;12 https://doi.org/10.2427/11522.

47. R Core Team. R development Core team. R: A Language and Environment for Statistical Computing. 2017:55:275-86:http://www.R-project.org.

48. QGIS Development Team. QGIS geographic information system. Open Source Geospatial Foundation Project. 2015; http://www.qgis.org/.

49. L'Azou M, Moureau A, Sarti E, Nealon J, Zambrano B, Wartel TA, et al. Symptomatic dengue in children in 10 Asian and Latin American countries. N Engl J Med. 2016;374:1155-66. https://doi.org/10.1056/NEJMoa1503877.

50. Undurraga EA, Halasa YA, Shepard DS. Use of expansion factors to estimate the burden of dengue in Southeast Asia: a systematic analysis. PLoS Negl Trop Dis. 2013;7:e2056.

51. Wai KT, Arunachalam N, Tana S, Espino F, Kittayapong P, Abeyewickreme W, et al. Estimating dengue vector abundance in the wet and dry season: implications for targeted vector control in urban and peri-urban Asia. Pathog Glob Health. 2012; 106:436-45. https://doi.org/10.1179/2047773212Y.0000000063.

52. Tsuzuki A, Duoc VT, Higa Y, Yen NT, Takagi M. High potential risk of dengue transmission during the hot-dry season in Nha Trang City, Vietnam. Acta Trop. 2009;111:325-9.

53. Ehelepola NDB, Ariyaratne K, Buddhadasa WMNP, Ratnayake S, Wickramasinghe M, Promprou S, et al. A study of the correlation between dengue and weather in Kandy City, Sri Lanka (2003 -2012) and lessons learned. Infect Dis Poverty. 2015:4:42.

54. Sarfraz MS, Tripathi NK, Tipdecho T, Thongbu T, Kerdthong P, Souris M. Analyzing the spatio-temporal relationship between dengue vector larval density and land-use using factor analysis and spatial ring mapping. BMC Public Health. 2012;12:853.

55. Seidahmed OME, Eltahir EABA. Sequence of flushing and drying of breeding habitats of Aedes aegypti (L.) prior to the low dengue season in Singapore. PLoS Negl Trop Dis. 2016;10:e0004842.

56. Eastin MD, Delmelle E, Casas I, Wexler J, Self C. Intra- interseasonal autoregressive prediction of dengue outbreaks using local weather and regional climate for a tropical environment in Colombia. Am J Trop Med Hyg. 2014;91:598-610.

57. Philippines: "The situation of dengue fever in Davao Region is alarming" Outbreak News Today. http://outbreaknewstoday.com/philippines-the-situationof-dengue-fever-in-davao-region-is-alarming-42161/. Accessed 22 May 2017.
58. Mulligan K, Dixon J, Joanna Sinn C-L, Elliott SJ. Is dengue a disease of poverty? A systematic review. Pathog Glob Health. 2015;109:10-8. https:// doi.org/10.1179/2047773214Y.0000000168.

59. Dengue cases reach 5,757 in Davao City; floods, poor sanitation blamed / Inquirer News. http://newsinfo.inquirer.net/521003/dengue-cases-reach5757-in-davao-city-floods-poor-sanitation-blamed. Accessed 23 May 2017.

60. Gama ZP, Nakagoshi N. Climatic variability and dengue Haemaorrhagic fever incidence in Nganjuk District, east java. Indonesia Acta Biol Malaysiana. 2013:2:31-9.

61. Focks DA, Barrera R. Dengue Transmission Dynamics: Assessment And Implications For Control. Working Paper for the Scientific Working Group on Dengue Research. 2006;2006:1-5.http://citeseerx.ist.psu.edu/viewdoc/ download?doi=10.1.1.612.689\&rep=rep1\&type=pdf

62. Alto BW, Temperature BD. Dengue virus infection in mosquitoes: independent effects on the immature and adult stages. Am J Trop Med Hyg. 2013;88:497-505.

63. Hardy JL, Rosen L, Kramer LD, Presser SB, Shroyer DA, Turell MJ. Effect of rearing temperature on transovarial transmission of St. Louis encephalitis virus in mosquitoes. Am J Trop Med Hyg. 1980;29:963-8.

64. Correia Filho WLF. Influence of meteorological variables on dengue incidence in the municipality of Arapiraca, Alagoas, Brazil. Rev Soc Bras Med Trop. 2017:50:309-14.

65. Lawrence MG. The relationship between relative humidity and the dewpoint temperature in moist air: a simple conversion and applications. Bull Am Meteorol Soc. 2005;86:225-33.

66. Mutheneni SR, Morse AP, Caminade C, Upadhyayula SM. Dengue burden in India: recent trends and importance of climatic parameters. Emerg Microbes Infect. 2017:6:e70

67. Capeding MRZ, L'Azou M, Manalaysay M, Vince-Woo CR, Rivera RG, Sy AK, et al. Laboratory-confirmed dengue in children in three regional hospitals in the Philippines in 2009-2010. Pediatr Infect Dis J. 2015;34:1145-51.

\section{Ready to submit your research? Choose BMC and benefit from:}

- fast, convenient online submission

- thorough peer review by experienced researchers in your field

- rapid publication on acceptance

- support for research data, including large and complex data types

- gold Open Access which fosters wider collaboration and increased citations

- maximum visibility for your research: over $100 \mathrm{M}$ website views per year

At BMC, research is always in progress.

Learn more biomedcentral.com/submissions 